to make the program and run the robot model. Implemented the lessons learned from the pilot study on the implementation and use of STEM approaches in the educational process and extracurricular activities in the context of continuity of education.

The Study focuses on a pressing theoretical problem - the problem of psychological nature and conditions of intellectual development. The direction of such research is of fundamental nature, since we are talking about developing a new concept for the development of children's intelligence during a research study of subjects of natural-mathematical cycle in the school. Calculating the correlation between the indicators of benefits in the students ' attitude to use of information resources and levels of intellectual development of students to particular groups of information resources used to perform correction of the author's technique of research training with the aim of pedagogically appropriate and methodologically motivated selection of educational resources to minimize contradictions with regard to levels of intellectual development of pupils, specific groups of students.

The materials are intended for teachers, will be useful to teachers and students of pedagogical universities.

Key words: variable models, simulation, computer oriented methodical system of research training, intellectual development, pedagogical design, research training, educational robotics, engineering education

DOI 10.31392/NPU-nc.series 2.2020.22(29).10

УДК 378.091.315.7:004.777-047.64

Ганна Миколаївна Качан

кандидат економічних наук, старший викладач кафедри теоретичних основ інформатики Національного педагогічного університету імені М.П. Драгоманова, ORCID ID 0000-0001-6378-2298

h.m.kachan@npu.edu.ua,

\title{
ОСОБЛИВОСТІ КУРСУ «УПРАВЛІННЯ ІТ-ПРОЕКТАМИ» В ЗАКЛАДАХ ВИЩОЇ ОСВІТИ
}

Анотація. У сучасних умовах розвитку інформаційної економіки пріоритетним напрямком $\epsilon$ розвиток у сфері інформаційних технологій. Розробка програмного забезпечення та програмнотехнічних комплексів $є$ досить складним проектом, управляння яким потребує спеціалізованих менеджерів проекту. У зв'язку з цим у середовищі професійних кадрів відчувається гостра нестача навичок з формалізації, підготовки та управління проектами. Отже, виникає нагальна потреба в опануванні світового досвіду розробки, аналізу, впровадження та управління проектами, особливо в сфері розробки інформаційних систем та програмного забезпечення.

В статті розглянуто особливості навчальної дисципліни «Управління IT-проектами» в закладах вищої освіти I-II рівня акредитації. Головну мету навчання дисципліни «Управління проектами» визначено як формування у студентів уявлення про методологію підготовки й реалізації, способи та засоби побудови проектів, залучення ресурсів для реалізації цих проектів і механізмів управління ними. Завдання дисципліни - дати студентам систему теоретичних знань і сформувати практичні навички у сфері планування, оцінки, моніторингу та супроводження проектів в IT-сфері.

Розкрито зміст навчальної дисципліни «Управління IT-проектами, яка розроблена для підготовки студентів за спеціальністю «Комп'ютерні науки» всіх форм навчання. Студенти здобувають комплекс знань та навичок, що дозволить розуміти процес управління проектами, практично використовувати засоби планування та реалізацію IT-проектів, розробляти вірну структуру плану виконання проектів, оволодіти практичними навиками користування інформаційними системами, в яких відбувається розробка та реалізація етапів реалізації проекту, призначення відповідальних за етапи виконання, писати технічні завдання з використанням регуляторних документів та відповідних ГОСТів.

Розглянуто деякі методичні аспекти навчання управління проектами як необхідну ланку професійної підготовки фахівців у галузі інформаційних технологій. Наведено короткий огляд найпоширеніших систем управління проектами: MS Project, Open Plan Professional та Project Expert. Навчання курсу повинне сприяти засвоєнню студентами базових знань, щодо принципів теорії управління проектами 3 розробки програмного забезпечення і набуття лабораторних навичок планування, контролю та оптимізації процесів розробки програмного забезпечення.

Ключові слова: управління, проект, ІТ-проект, технології, системи, програмне забезпечення, програма. 
Дуже важливими для багатьох комерційних і державних організацій є програми та проекти, адже завдяки їх використанню з'являється можливість істотно збільшити свій прибуток, особливо під час поставок замовникам складної високотехнологічної продукції та систем.

Проекти є інструментом й удосконалювання державних організацій на всіх рівнях: міста, регіону, країни. За допомогою програм i проектів різноманітні установи вводять нові $\mathrm{i}$ удосконалюють уже надавані ними послуги. Але у всіх цих організаціях - державних, суспільних i комерційних - відзначається, що, хоча в них фактично ведеться багато проектів, в багатьох випадках вони часто погано продумані й позбавлені належного управління [[5], с. 12].

В провідних університетах економічно-розвинутих країн управління проектами давно вже стали невід'ємною частиною навчальних програм. Стрімкий розвиток інформаційного суспільства та потреба в фахівцях, які володіють знаннями про інструменти і методи управління проектами та навичками їх практичного застосування, визначили необхідність впровадження курсу «Управління IT-проектами» для студентів інформатичних та економічних спеціальностей закладів вищої освіти як обов'язкової дисципліни.

За допомогою використання методів управління проектами можна досягти якісних результатів, заощадити час, ресурси, гроші, знизити ризик та підвищити надійність реалізації проектів. Досвід Німеччини, Японії, США, Великобританії свідчить про те, що концепція управління проектами потужний засіб виходу 3 економічної кризи і розв'язування великих виробничих, наукових i соціальних проблем. Оскільки ця концепція сприяє досягненню необхідної якості у встановлені терміни в рамках прийнятого бюджету, вона є інструментом управління в умовах, що змінюються, в умовах нестабільності та невизначеності. За допомогою використання методів управління проектами можна ефективно управляти часовими, витратними, якісними параметрами майбутньої продукції або послуги [[1], с.10].

Серед науковців, які досліджують проблеми інформатизації освіти, слід відзначити праці: А.П. Єршова, М.І. Жалдака, В.В. Лаптєва, М.П. Лапчика, В.М. Монахова, Н.В. Морзе, С.А. Ракова, Ю.С. Рамського, 3.С. Сейдаметової, С.О. Семерікова, О.М. Спіріна, Ю.В. Триуса, С.М. Яшанова та ін.

Основоположниками теорії управління проектами вважаються Генрі Гант, Анрі Файоль i Фредерік Тейлор. Серед українських вчених вагомий внесок у розвиток знань з управління проектами здійснили: С.Д. Бушуєв, Н.С. Бушуєва, В.В. Морозов, В.А. Рач.

Розвиток української економіки характеризується проведенням проектів реструктуризації та реорганізації підприємств всіх галузей національного господарства. Для проекту обов'язковими $\epsilon$ інформаційна взаємодія 3 іншими підприємствами та установами, a також управління інформаційними зв'язками всередині проекту. Для ефективного управління створюються спеціальні інформаційні технології, а результатом їх впровадження $є$ інформаційно-управлінські системи. Управління інформаційними проектами означає планування, організацію та управління ресурсами для досягнення мети 3 максимальною ефективністю

Проект - це обмежений часовими рамками процес, що має визначений початок та кінець, зазвичай обмежений датою, але також може обмежуватися фінансуванням або досягненням результатів, який здійснюється для реалізації унікальних цілей та завдань, зазвичай, щоб призвести до вигідних змін або створення доданої вартості. Проект - це тимчасовий захід, призначений для створення унікальних товарів та послуг [[3], с. 7]. Отже, проект - це комплекс взаємозалежних заходів, що спрямовані на досягнення поставлених цілей з обмеженнями у часі, фінансових та інших ресурсів, в умовах виникнення можливих несприятливих ситуацій і ризиків. А управління проектом процес управління командою і ресурсами проекту за допомогою специфічних методів, завдяки яким проект завершується успішно і досягається поставлена мета [[4], с. 22].

За допомогою систем управління IT-проектами можна аналізувати ризики, створювати календарне планування робіт, розраховувати ресурси і витрати, організовувати роботу персоналу, контролювати процес виконання проекту, візуалізувати структуру IT-проекту та звіту, інтегрувати 3 іншими прикладними програмними засобами тощо.

Особливістю простих систем управління ІТ-проектами є простота їх використання, швидкість отримання результату і головне, що користувачу не обов'язково бути спеціалістом. Для професійних систем характерні гнучкі засоби планування і контролю, але на підготовку і аналіз даних знадобиться більше часу кваліфікованих користувачів.

Відповідно до сучасних тенденцій управління проектами передбачається збільшення ролі використання інформаційних технологій. Використання інформаційних систем управління проектами дає можливість підвищити ефективність управління та зменшити відсоток незавершеності проектів, управляти змінами, ресурсами, обмеженнями, комунікаціями, робочою командою та іншими факторами, від яких залежить виконання проекту. До систем автоматизації управління проектами включаються такі структурні елементи: засоби для календарно-сітьового планування, засоби 
розв'язування окремих задач (серед них слід виокремити допроектний аналіз, розробку бізнес-планів, аналіз ризиків, управління термінами, управління витратами), засоби для організації комунікацій між виконавцями проекту [[2], с. 101-102].

Дисципліна призначена для надання системних відомостей про використання засобів планування, процесу управління проектами та інструментарії для ефективного управління роботою.

Базовими для даного навчального курсу є знання, уміння і навички, набуті студентами після закінчення загальноосвітніх навчальних закладів та з дисциплін попередніх курсів: алгоритмізація та програмування, системний аналіз та об'єктно-орієнтоване програмування.

Дисципліна «Управління IT-проектами» за навчальним планом підготовки бакалавра належить до нормативної частини циклу професійної та практичної підготовки, передбачається проведення лекційних та лабораторних занять з використанням засобів сучасних ІКТ. Загальна кількість годин $\underline{120}, 3$ них 52 аудиторних: $\underline{26}$ годин - лекційні заняття, $\underline{26}$ годин - лабораторні. Значна увага приділяється самостійній роботі студентів - $\underline{68}$ годин. Вона полягає у підготовці студентів до аудиторних занять, виконанні завдань, що пропонуються на лекційних і лабораторних заняттях, опрацюванні спеціальної літератури для підготовки питань, що винесені на самостійне опрацювання, у підготовці до модульного контролю, роботі з електронним матеріалами в системі MOODLE [[6], c.7].

Навчання даного курсу забезпечується використанням навчально-методичної літератури, розробленими завданнями та інструкціями до занять, програмним забезпеченням i технічними засобами навчання.

У лекційному курсі передбачається розкрити мету і завдання навчання навчальної дисципліни «Управління IT-проектами», основні поняття, принципи, положення, їх теоретичне та прикладне значення. На лабораторних заняттях студенти знайомляться з сучасними програмними засобами щодо створення проектів, набувають уміння і навички роботи 3 ними. Виконання завдань лабораторних занять сприяє розвитку творчої самостійності студентів, розвиває їх інтерес до науки $\mathrm{i}$ наукових досліджень.

В лекційному курсі розглянуто питання про основні поняття управління проектами, системні підходи та методи управління проектами; класифікацію задач під час управління проектами; роль та відповідальність членів проектної команди; моделі життєвого циклу розробки програмного забезпечення; концепцію управління ризиками, методами і засобами ї ідентифікації, а також оцінювання і мінімізацію негативних наслідків; управління персоналом проекту в системі управління проектами та методику формування витрат за проектом.

Під час виконання лабораторних робіт студенти вивчають основні поняття, структуру і вимоги створення та функціонування проектного управління. Завдяки послідовному виконанню лабораторних робіт формується цілісне бачення системи управління проектом, який починається 3 мережевого планування і закінчується звітами щодо виконання проекту. Студентами вивчаються питання методів планування, визначення меж проекту, розподіл ресурсів, рівень деталізації робіт, управління часовими критеріями тощо. Для кожного студента розроблені індивідуальні завдання, що обираються відповідно до списку в журналі. На захист лабораторної роботи студенти оформлюють окремий звіт. Виконання поставлених завдань дає можливість студентам правильно планувати роботу під час написання бакалаврської роботи і магістерського проекту, здобути знання, необхідні для отримання кваліфікації фахівця в сфері управління проектами та керівника інформаційно-технічним відділом.

Розглянемо детальніше питання програмних засобів, що вивчаються студентами в рамках даної дисципліни. В Україні існує велика кількість програмних засобів для розв'язування задач стосовно управління проектами. Найпоширеніші з них можна класифікувати за такими критеріями:

1) Програмні засоби, орієнтовані на автоматизацію послуг:

- ARTA Software - системa ARTA Synergy;

- Epicor Software;

- IFS Applications;

- Microsoft Project Professional;

- Oracle E-Business Suite;

- PeopleSoft Project Management;

- Primavera;

- SAP Professional Services Automation.

2) Системи управління проектами і завданнями:

- MS Project - система управління проектами; 
- Open Plan Professional - професійна система управління проектами, яка характеризується потужними засобами ресурсного і бюджетного планування;

- Project Expert - система для підготовки бізнес планів та створення фінансових моделей нового або діючого підприємства незалежно від його галузевої належності і масштабів;

- Bontq - система управління проектами та відслідковування помилок;

- Cerebro - система управління проектами в аудіовізуальній сфері;

- eGroupWare - безкоштовне ПЗ для управління проектами;

- GanttProject - маленька безкоштовна програмка з діаграмою Ганта та ресурсами;

- Kommandcore - платний багатокористувацький веб-сервіс з управління проектами, призначений в першу чергу для керівників проектами, заснований на методології гнучкої розробки;

- OpenProj - безкоштовна, відкрита альтернатива Microsoft Project;

- РауDox - система управління документами, завданнями і спільною роботою співробітників.

- Project Kaiser - веб-орієнтована система управління проектами і завданнями з підтримкою wiki i розвиненими засобами забезпечення взаємодії користувачів;

- ProjectMate - Російська PSA-система автоматизації професійної діяльності. Крім модуля управління проектами передбачено масу функцій, затребуваних в компаніях сфери консультаційних послуг: починаючи від обліку часу і закінчуючи виставленням рахунків (білінгом);

- Redmine - безкоштовний багатокористувацький веб-сервіс, орієнтований на специфіку ITпроектів і розробників;

- TeamLab - система для управління проектами, документами та спільної роботи;

- TrackStudio Enterprise - система управління завданнями;

- Trac - інструмент управління проектами та відслідковування помилок в програмному забезпеченні;

- Web2Project - відкритий безкоштовний веб-додаток для управління проектами (проект заснований на коді dotProject) [[8], с. 33-34].

Доцільно надати короткий опис кількох відомих інформаційних систем управління проектами.

MS Project (рис. 1) - найбільш поширена і доступна система управління IT-проектами. За даними корпорації Microsoft, вже зареєстровано близько 8 мільйонів користувачів. Перевагами MS Project $€$ : простий інтерфейс, можливість працювати користувачам різних рівнів, зручні засоби створення звітів та покрокова розробка ІТ-проекту. Основним недоліком вважається малий набір засобів для планування та управління ресурсами. За допомогою MS Project можливо здійснювати планування та управління лише людськими ресурсами і обладнанням. У багатьох західних компаніях MS Project $\epsilon$ стандартним компонентом Microsoft Office, який використовують навіть рядові співробітники для планування робіт.

> Open Plan Professional (рис. 2) - друга поширена система управління IT-проектами, для якої характерні потужні засоби ресурсного і бюджетного планування. Основні функції Open Plan Professional: створення моделі IT-проекту, управління ресурсами, планування і контроль витрат, аналіз ризиків та багатопроектне планування.

Використання системи Open Plan дає можливість управляти усіма видами ресурсів, а саме: людськими, фінансами, обладнанням та матеріалами. Ресурси поділені на категорії: відновлювальні, невідновлювальні, загальнодоступні та такі, що надаються лише користувачам 3 відповідними правами доступу до цих даних.

В системі Open Plan можливе відображення результатів вартісного аналізу проектування та розробки IT-проекту. Крім того можна спланувати розробку IT-проекту у найменш завантажений період ресурсами відповідної кваліфікації [9].

$>$ Project Expert (рис. 3) - програмний засіб, створений для розробки фінансових моделей підприємств, розробки стратегічного плану і підготовки бізнес-плану та аналізу фінансової ефективності бізнес-проектів. Project Expert вважається однією з найкращих систем і став стандартом для бізнес-планування та оцінювання інвестиційних проектів в Росії, країнах СНГ і Балтії. 


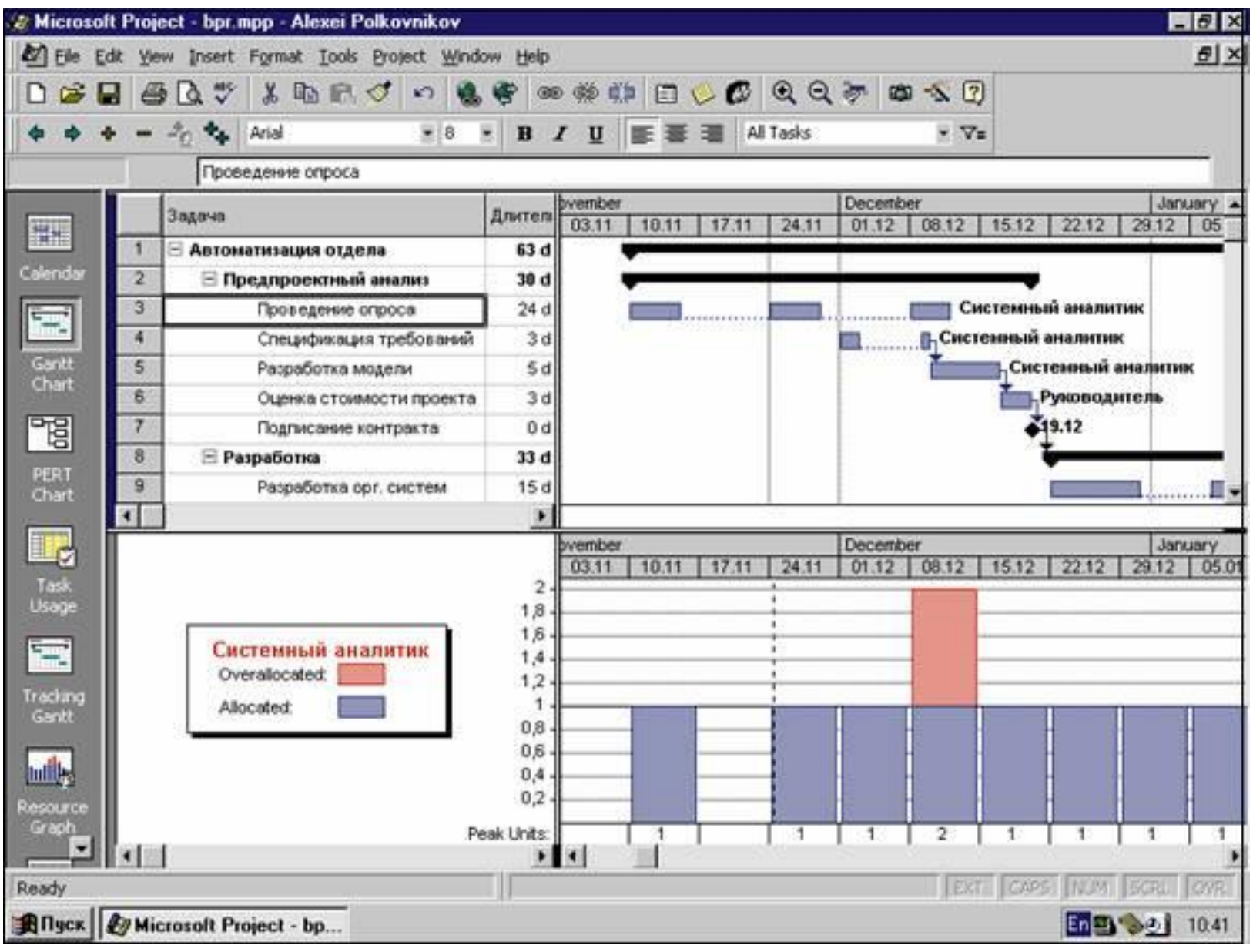

Puc 1. MS Project

\section{Open Plan Cross Project Analysis}

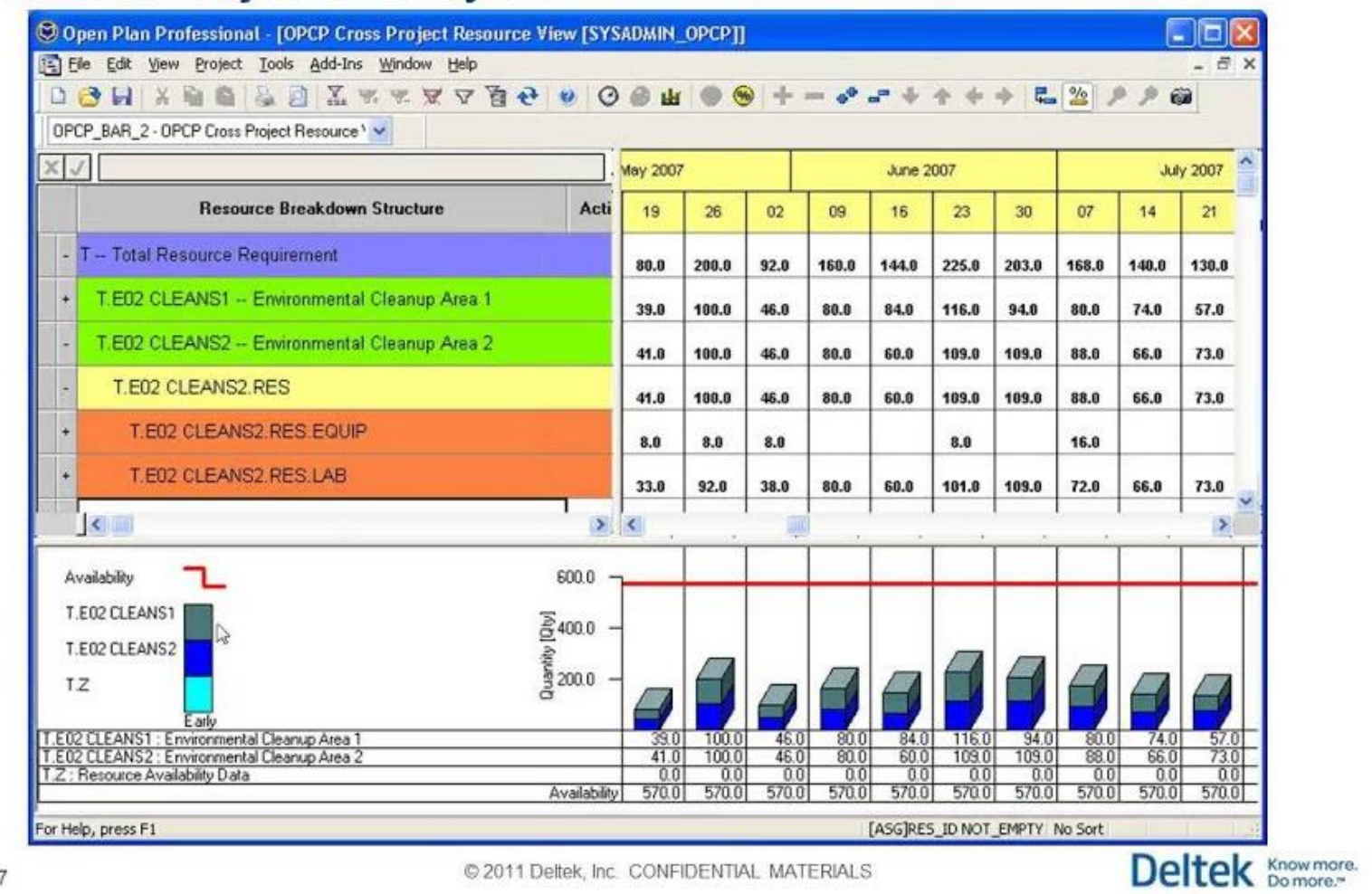

Puc. 2. Open Plan Professional 


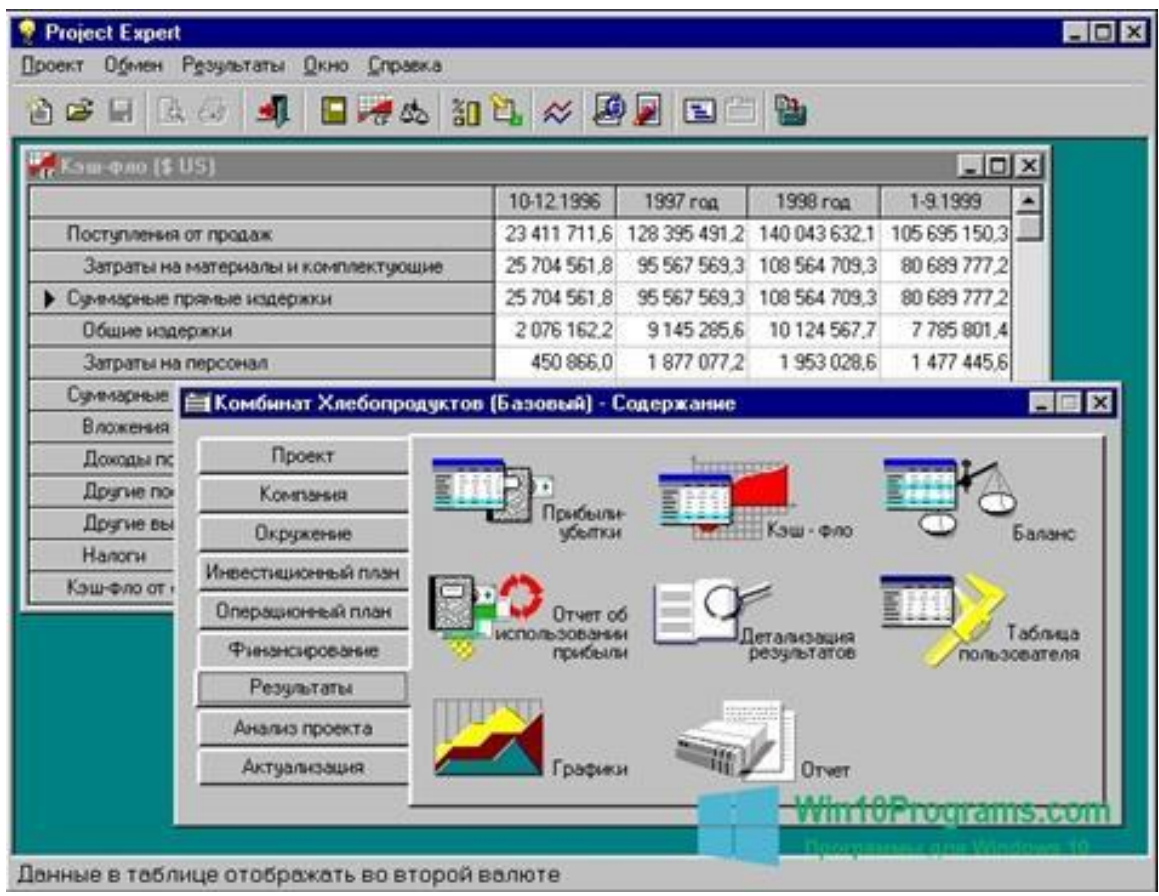

Puc. 3. Project Expert

Використання програмного засобу Project Expert дає змогу створювати модель діяльності різних галузей та масштабів. Систему часто використовують під час фінансового моделювання і розробки бізнес-планів підприємства, надання послуг в банківських установах, будівництві, переробній і легкій промисловості, машино будівництві, енергетиці тощо.

Формою підсумкового контролю результатів навчання студентів є іспит, мета проведення якого полягає у перевірці системності засвоєння програмового матеріалу, цілісності бачення навчального курсу, рівня осмислення знань та набуття умінь, їх комплексного застосування у практичній діяльності, діагностуванні ефективності самостійної навчальної роботи студентів.

Допуск до екзамену має студент за умови набору більше 60 рейтингових балів, а саме:

- регулярного відвідування лекційних і лабораторних занять або їх негайного відпрацювання, своєчасного складання усіх видів поточного контролю з позитивними результатами;

- поглибленні набутих знань у процесі самостійної роботи;

- засвоєнні змісту навчального курсу в обсязі, передбаченому в галузевому стандарті вищої освіти.

Зразок екзаменаційного білету (рис. 4):

\begin{tabular}{|c|c|c|}
\hline Націонал & $\begin{array}{l}\text { едагогічний університет імені М.П. Драгоманова } \\
\text { Факультет інформатики }\end{array}$ & \\
\hline Освітньо-кваліфікаційннй ступінь & бакалавр & \\
\hline Галузь знань & 12 Інформадійні технології & \\
\hline Напрям підтотовки & $\begin{array}{l}122 \text { Комп'ютерні науки та інформанійні } \\
\text { технологій }\end{array}$ & Cessectp VIII \\
\hline Навчальна дисцитліна & «Управління ТТ-проектамю» & \\
\hline
\end{tabular}

\section{ЕКЗАМЕНАЦЙНИЙ БLЛЕТ № 13}

1. Управління термінами виконання проекту.

2. Ризики проекту: причини ризику, умови виникнення, наслідки та вартість.

3. Практичне задання.

Створити проект інформатизацій відділу маркетингу фірми.

Трнватість проекту має бути не менше 4 місяців.

Виконати такі зміни в календарі робочого часу: визначити один святковий тикдень; головний спедіаліст 3 маркетингу перебуває у відпустці протягом трьох тикнів другого мкісяи (за катендарем) від початку виконання проекту.

Виконати складне сортування в продесі перегляду діаграхи Ганта за початковою датою (за зростаннмм) та триватістю виконання робіт (за спаданням).

Затверджено на засіданні кафедри інформаційних технологій та програмування

Рис. 4. Зразок екзаменаційного білету 
Оцінювання відповідей на екзамені здійснюється так: 1 питання - 25 балів, 2 питання - 25 балів, 3 питання - 50 балів [[6], с. 16].

Для дистанційної підтримки навчання дисципліни «Управління IT-проектами» було розроблено дистанційний курс, в якому розміщено лекційні матеріали, завдання до лабораторних робіт, теоретичні відомості і тестовий контроль.

В сучасних умовах неможливо забезпечити якісну підготовку майбутнього бакалавра 3 інформаційних технологій проектування без цілісного уявлення про процес управління проектами. Тому підготовка майбутніх фахівців повинна включати формування необхідних умінь, знань i навичок в галузі проектування, зокрема у процесі навчання основ управління IT-проектами.

3 огляду на загальні тенденції розвитку проектного управління в сучасних умовах можна констатувати, що особливо важливим завданням у цьому напрямку є поширення національних стандартів з управління проектами, підвищення рівня знань щодо системи управління проектами серед управлінців різних рівнів, сертифікація проект-менеджерів. Це допоможе типізувати проектну діяльність і значно спростити процеси взаємодії в межах кожного конкретного проекту, встановивши базові методи управління проектами як в державних, так і в приватних компаніях та організаціях [[7], c. 175].

В подальшому необхідні теоретичні дослідження в напрямі впровадження інформаційних технологій для автоматизації ефективного управління кількома проектами одночасно та контролю їх виконання.

\section{Список використаних джерел}

[1] Бредіхін В.М., Тарасенко С.І. Управління проектами: проблеми та перспективи. Молодий вчений. № 4.4 (44.4). Київ, 2017. С. 9-12.

[2] Василевська А. Управління проектами підприємства із використанням інформаційних технологій. Вісник КНТЕУ. Системні дослідження. №1. Київ, 2012. С. 99-105.

[3] Демиденко М.А. Управління проектами інформатизації. Навчальний посібник. НГУ, Дніпропетровськ, 2014. 114 с.

[4] Довгань Л.С., Мохонько Г.А., Малик І.П. Управління проектами. Навчальний посібник. Київ: КПІ ім. Ігоря Сікорського, 2017. 420 с.

[5] Катренко А.В. Управління ІТ-проектами. Стандарти, моделі та методи управління проектами. Львів, 2011. $550 \mathrm{c.}$

[6] Качан Г.М. Управління IT-проектами. Програма нормативної навчальної дисципліни освітнього ступеня бакалавр галузі знань 12 Інформаційні технології напрям підготовки 122 Комп’ютерні науки та інформаційні технології. Київ: Вид-во НПУ імені М.П. Драгоманова, 2020. 19 с.

[7] Павлова C.I. Проектно-орієнтовані організації як розвиток методів управління підприємством. Вісник ЖДТУ. Серія: Економічні науки. № 4 (78). 2016. С. 170-176.

[8] Хлобистова О.А, Гладка М.В. Управління IT проектами: Лабораторний практикум для студентів напряму підготовки 6.050101 «Комп'ютерні науки» денної та заочної форм навчання. Київ: HУXT, 2013. 108 c.

[9] Open Plan и другие: семейство программных пакетов Welcom для управления проектами. 2008. URL: https://blog.iteam.ru/open-plan-i-drugie-semejstvo-programmnyh-paketov-welcom/ (Дата обращения: 06.01.2020).

\section{References}

[1] Bredixin V.M., Tarasenko S.I. (2017) Project management: problems and prospects. A young scientist. 4.4 (44.4). Kyiv, P. 9-12. (in Ukrainian).

[2] Vasylevs"ka A. (2012) Enterprise project management using information technology. Visnyk KNTEU. Systemni doslidzhennya. 1. Kyiv. P. 99-105. (in Ukrainian).

[3] Demydenko M.A. (2014) Informatization project management. Educational manual. NHU, Dnipropetrovs"k, 114 p. (in Ukrainian).

[4] Dovhan" L.Ye., Moxon"ko H.A., Malyk I.P. (2017) Project management. Educational manual. Kyiv: KPI im. Ihorya Sikors"koho, 420 p. (in Ukrainian).

[5] Katrenko A.V. (2011) IT project management. Standards, models, and methods of project management. Lviv, 550 p. (in Ukrainian).

[6] Kachan H.M. (2020) IT project management. The program of normative educational discipline of the educational degree bachelor of the field of knowledge 12 Information technologies direction of preparation 122 Computer sciences and information technologies. Kyiv: NPU imeni M.P. Drahomanova, 19 p. (in Ukrainian). 
[7] Pavlova S.I. (2016) Project-oriented organizations as the development of enterprise management methods. Visnyk ZhDTU. Seriya: Ekonomichni nauky. 4 (78). P. 170-176. (in Ukrainian).

[8] Xlobystova O.A, Hladka M.V. (2013) IT project management: Laboratory workshop for students majoring in 6.050101 "Computer Science" full-time and part-time education. Kyiv: NUXT, 108 p. (in Ukrainian).

[9] Open Plan and others: the Welcom family of project management software packages. (2008) URL: https://blog.iteam.ru/open-plan-i-drugie-semejstvo-programmnyh-paketov-welcom/ (Accessed date: 06.01.2020).

\title{
Kachan Hanna
}

\section{FEATURES OF IT-PROJECT MANAGEMENT COURSE IN HIGHER EDUCATION INSTITUTIONS}

\begin{abstract}
In today's conditions of development of the information economy, the priority area is the development in the field of information technologies. Software and software development are a complex project that requires specialized project managers to manage. As a result, there is a severe lack of formalization, preparation, and project management skills in the professional environment. Therefore, there is an urgent need to master the global experience of developing, analyzing, implementing, and managing projects, especially in the field of information systems and software development.

The article deals with the peculiarities of the discipline "IT Project Management" in higher education institutions of I-II accreditation level. The main purpose of teaching the discipline "Project Management" is defined as the formation of students' ideas about the methodology of preparation and implementation, ways and means of project construction, attracting resources for the implementation of these projects and mechanisms for managing them. The objective of the course is to give students a system of theoretical knowledge and to develop practical skills in the field of planning, evaluation, monitoring and support of projects in the IT field.

The content of the course "IT Project Management", which is designed to prepare students in the specialty "Computer Science" of all forms of training, is disclosed. Students acquire a complex of knowledge and skills that will allow them to understand the process of project management, to practically use the means of planning and implementation of IT projects, to develop the right structure of the project implementation plan, to acquire practical skills of using information systems in which the development and implementation of project implementation stages, assigning responsible for stages of implementation, to write the terms of reference using the regulatory documents and relevant GOST.

Some methodological aspects of project management training are considered as a necessary link of professional training of specialists in the field of information technologies. A brief overview of the most common project management systems: MS Project, OpenPlan Professional and Project Expert. The course training should facilitate students' acquisition of basic knowledge of the principles of project management theory in software development and the acquisition of laboratory skills in planning, controlling, and optimizing software development processes.
\end{abstract}

Keywords: management, project, IT project, information technology, information systems, software, training program.

DOI 10.31392/NPU-nc.series 2.2020.22(29).11

УДК 004.42:519.6

Олександр Юрійович Мельников ${ }^{1}$, Олександр Сергійович Сокольський ${ }^{2}$ Донбаська державна машинобудівна академія, м. Краматорськ, Україна ${ }^{1}$ кандидат технічних наук, доцент, доцент кафедри інтелектуальних систем прийняття рішень ORCID ID: 0000-0003-2701-8051 alexandr@melnikov.in.ua

${ }^{2}$ студент спеціальності «Системний аналіз» ORCID ID: 0000-0002-3933-5057 SokolMag2380@gmail.com

\section{СПЕЦІАЛЬНЕ ЗАСТОСУВАННЯ ВЛАСНОЇ РОЗРОБКИ ДЛЯ ДЕМОНСТРАЦІї І ПОРІВНЯННЯ АЛГОРИТМІВ СОРТУВАННЯ ТА ПОШУКУ ДАНИХ}

Анотація. У статті наведено опис спеціального застосування власної розробки, яке дозволяє студентам, що вивчають алгоритми сортування та пошуку даних, спостерігати за процесом i 